\title{
The effect of Benson's muscle relaxation technique on severity of pregnancy nausea
}

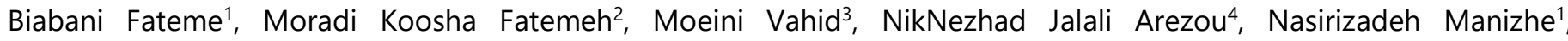 \\ Moradi Zahra ${ }^{6}$
}

\begin{abstract}
Introduction: Nausea and vomiting caused by pregnancy significantly affect the quality of life of pregnant women and cause problems in them. The aim of this study was to evaluate the effect of muscle relaxation technique on nausea during pregnancy.

Materials and Methods: This study was a controlled clinical trial. 44 pregnant women referred to the health center were randomly divided into two groups: control and test. Benson's muscle relaxation was taught to the test group during three sessions. They were then asked to do relaxation for 1520 minutes for one month twice a day. No training was provided for the control group. The severity of nausea was compared using visual analogue vomiting (VAS) in two groups and the obtained results were analyzed using Wilcoxon, Kruskal-Wallis and Mann-Whitney tests at a significant level of $\leq 0.05$.

Results: Based on obtained results, 39.1\% of mothers were aged between 30-35 years old. The mean and standard deviation of severity of nausea in the intervention (test) group before Benson relaxation was $6.9 \pm 2.9$ and after relaxation was $6.64 \pm 1.99$. Analysis (Mann-Whitney test) of severity of nausea before and after intervention in the test group showed a significant difference.

Conclusion: Considering the positive effect of Benson's relaxation on the reduction of nausea and vomiting in pregnancy, its education is recommended for all pregnant women in the first trimester of pregnancy in health and counseling centers.
\end{abstract}

Keywords: muscle relaxation, nausea, pregnancy

\section{INTRODUCTION}

Nausea and vomiting occur in $70 \%$ of pregnancies, and almost $50 \%$ of pregnant women experience vomiting alone (1 and 2). Although this is not a life-threatening problem, it can be stressful both for pregnant women and for their families (3). Nausea and vomiting during pregnancy can have a profound effect on the life and performance of pregnant women, including a significant reduction in the quality of life, individual and social performance of them. This problem usually begins at 4 th week and is maximized at 10 to 15 th week and symptoms disappear in the 20th week of pregnancy. In 50 to $55 \%$ of pregnant women, symptoms continue after 20th week of pregnancy and sometimes even to the end. Symptoms in most cases are nausea, retching, vomiting and avoid the smell of food (4). Various studies have indicated several factors for nausea and vomiting in pregnancy. Psychological and social factors are also important and vomiting may be more in people with unwanted pregnancy, although these factors are not the primary cause but they are effective in severity (5). For the first time, Dolly posed the relatedness of psychological problems with nausea and vomiting of pregnancy. In his view, the fear of not accepting the role of mother and unwanted pregnancy shows itself as physical symptoms such as nausea and vomiting (6). Fairweath said that more than 80 percent of severe cases of nausea and vomiting have a psychological source (7). The uncertainty about the main cause of nausea and vomiting in pregnancy

\footnotetext{
Msc. Nursing, East Nursing and Midwifery Research Center, Instructor, Faculty of Nursing and Midwifery college, Birjand University of Medical Sciences, Birjand, Iran

2 Msc. School of Nursing and Midwifery, Gonabad University of Medical Sciences, Gonabad, Iran

3 Msc. Department of Operating Room, Neyshabur University of Medical Sciences, Neyshabur, Iran

4 Msc. Nursing department, Sabzevar branch, Islamic Azad University, Sabzevar, Iran

${ }_{5}$ Msc. Nursing. Department of Nursing, Neyshabur University of Medical Sciences, Neyshabur, Iran
}

Correspondence: Moradi Zahra

Department of Nursing, Neyshabur University of Medical Sciences, Neyshabur, Iran

E-mail:moradiz1@nums.ac.ir

Received: 26 Feb 2018, Accepted: 13 Apr 2018

(C) 2019 by the authors; licensee Modestum Ltd., UK. This article is an open access article distributed under the terms and conditions of the Creative Commons Attribution License (http://creativecommons.org/licenses/by/4.0/). 
has led to a problem in finding specific treatment. Most of the therapies are supportive. Pharmacotherapy also has side effects and rarely can be so successful that it causes the mother to get rid of symptoms. Therefore, the use of complementary therapies can be a solution to this problem (8). One of these complementary therapies is relaxation. Relaxation has several methods, but the method introduced by Herbert Benson in 1970 is more desirable for others because of its easy learning and training (9). Benson's relaxation is one of the methods of focusing on the senses that affect a wide range of physical and psychological symptoms such as anxiety, pain, depression, mood and self-confidence and reduces stress (10). As a result of his research, Benson points out the value of détente (relaxing of tension). He believed that détente is a key element for the effects of care. In his study on various stress-relieving methods, he concluded that the four essential elements increase détente, including: a relaxed environment, a comfortable state, a mental device such as the word to focus on and the passive attitude. This technique should be done in a relaxed environment, in a comfortable state, in mental concentration, and in a positive attitude to make a real impact (11). Benson relaxation does not have muscle contraction because muscle contraction increases the number of pulses, respiration and blood pressure, and increases the burden of the heart (12). Behavioral interventions such as relaxation are methods that patients can independently carry out as self-care strategies. This method is completely non-invasive and may reduce the need for patients to use anti-vomiting drugs. This method has less side effects and it saves the cost of hospitalization (13). Since muscle relaxation can reduce heart rate, decrease blood pressure and increase vasovagal blood flow and reduce the activity of the sympathetic system (14), it is expected to reduce nausea. However, since the main causes of vomiting caused by chemotherapy are the stimulation of centers susceptible to chemicals in the brain and the automated nervous system and psychosocial factors (15), is different with nausea due to pregnancy that for other than reasons. Also, the mean depression in pregnant women in Iran has been reported since 1996 to 2011 in a review article 27.6 (16). In the meantime, this technique reduces the stress of hemodialysis patients. Considering all of above mentioned and that one of the important reasons for pregnancy nausea and vomiting is psychological, and given so far, there has been no study on the effect of relaxation on nausea and vomiting of pregnancy, we decided to study the present study entitled "the effect of muscle relaxation on nausea and vomiting of pregnancy".

\section{METHODS}

This study was a rondemized clinical trial study with control group and the study population consisted of all pregnant women in the first trimester of pregnancy in the health center of Nehbandan city in the year 2015. After obtaining a permit for the implementation of the project at Birjand University of Medical Sciences with the ethics code GMUFEC1393.10 from Gonabad University of Medical Sciences and obtaining informed consent from the patients, the samples were selected according to inclusion and exclusion criteria and randomly groups of test and control using blocking method with four blocks. The number of control and test groups was equally selected. The inclusion criteria of the study included: having 4-12 weeks of pregnancy, having complete vigilance, listening and speaking ability to learn relaxation, having a desire to participate in research, lack of a known mental illness such as severe anxiety and depression, lack of medication anti-nausea and vomiting (antiemetic), lack of history of known muscular ailments, and lack of nausea for reasons other than pregnancy, such as nausea due to certain medications, food poisoning and digestive problems. Exclusion criteria included reluctance to continue cooperation, any conditions that are created for the patient during an intervention that makes it impossible for the intervention to be continued, such as death, travel and hospitalization, nonattendance at the educational sessions, and failure to do relaxation techniques for 5 sessions.

The sample size was calculated using the formula for comparing the means after the pilot study, taking into account the confidence coefficient of 0.95 and test power of $80 \%$ was calculated 20 subjects in each group and for the probable loss of sample for each group, 22 subjects were included.

The tools used in this study were demographic information questionnaire in two parts of personal information (sex, age, marital status, level of education, occupation), and information about disease and treatment (history of hypertension and diabetes, cesarean section, and stillbirths ...) and visual form of nausea (visual analogue vomiting) (VAS) and a relaxation form.

The tool for measuring the severity of nausea (VAS), which validity and reliability has been confirmed in various studies, is a scale of $100 \mathrm{~mm}$ long vertical lines, numbered from 0 to 100 . On the one hand, the phrase without nausea and the other side is the phrase nausea. To measure the severity of nausea with this tool, while showing it to the patient, he/she is asked to indicate the severity of the nausea at that moment by marking the mark on this line, then the severity of nausea by calculating the distance from the mark location from zero point (without nausea) is determined. 
Content validity was used for validity of the tool, and the reliability of this criterion was obtained in one of the studies carried out abroad with a correlation coefficient of 0.83 that was obtained from the comparison of the two-fold measurement of the severity of nausea within 10-15 minutes intervals (17), subsequently, a nausea visual questionnaire was used to measure the severity of nausea in both groups to complete it and deliver it to the researcher.

The method was done so that patients were first asked to complete the demographic questionnaire and the severity of nausea form. Then, Benson's relaxation technique was individually trained to the subjects in the two sessions. Afterwards, patients performed relaxation techniques for one month twice daily for 20-15 minutes each day. The procedure was as follows: 1 . The patient is slowly placed in a comfortable position, 2. Close the eyes slowly, 3. Relax slowly all muscles of the body from the lower legs, gradually relaxing towards the face and keep calm down, 4 . Breathe through nose and be aware of his/her own breath and slowly remove the breath from the mouth, and when breath comes out, repeat the number 1 under the lips and breathe out comfortably and normally, 5. Do this 20-15 minutes and try to relax the muscles, then slowly open your eyes and do not go up for a few minutes. Doesn't worry if he/she has reached a deep level of calm or not, letting relaxation is occurred with its song. When the disturbing thoughts come, try to ignore it and be indifferent to it (18). In order to achieve this goal, calls and even frequent reminders to the patient for the technique, as well as on-site visits and assistance from other members of their family to indirectly supervise the patient in performing the technique, as well as complete the checklist made by the researcher were used. There was no intervention for the control group. After six weeks, nausea was again compared between the control and intervention groups and the obtained results using Fisher's exact, Wilcoxon, Kruskal-Wallis and Mann-Whitney tests by use of software SPSS version 21 were analyzed.

\section{RESULTS}

Based on the results, the mean age of the subjects was $29.01 \pm 5.29$ and the majority of the samples were between the ages of 30 and 35 years old. The majority level of education was a secondary school, and the job of majority of subjects was housekeeper. The mean gestational age was $10.2 \pm 32.2$ weeks. $68.2 \%$ of the samples had no history of diabetes and $63.6 \%$ of them have no history of hypertension and the abortion history was $29.5 \% .84 .1 \%$ of the samples had no history of stillbirth. The mean number of live births in each of the research subjects was $1.70 \pm 1.21$, and the majority of the subjects (29.5\%) had two live births (Table 1). According to Chi-square test, two groups of test and control were not significantly different from the demographic variables of age, maternal age, gestational age, education and occupation, history of stillbirth, history of gestational diabetes, a history of hypertension and were homogenous. Also, in relation to disease information, most of the subjects did not have a history of hypertension and had a history of gestational diabetes. The gestational age was between 4 and 16 weeks. The Chi-square test did not show significant difference in terms of the variables mentioned in the two groups and in this regard, the groups were homogeneous.

Regarding the severity of nausea in the pre-interventional stage, according to the table, mean score of the severity of nausea in the intervention group was higher than that of the control group, and the Mann-Whitney test did not show a significant difference between the two groups $(p=0.44)$. The mean score of severity of nausea after the intervention in the control group was higher than the intervention group and the Whitney test showed a significant difference between the two groups $(p=0.04)$. In examining the mean difference between the severity of nausea before and after intervention in the two groups it was found that the mean of nausea severity decreased in the intervention group and decreased in the control group and the Mann-Whitney test revealed that this technique significantly reduced the severity of nausea $(p=0.001)$ (Table 2). 
Table 1: Distribution of research samples according to demographic characteristics

\begin{tabular}{|c|c|c|c|c|c|}
\hline Variable & Subgroup & $\begin{array}{c}\text { Control } \\
\text { Percentage (number) / } \\
\text { standard deviation } \pm \text { Mean }\end{array}$ & $\begin{array}{c}\text { Intervention } \\
\text { Percentage (number) / } \\
\text { standard deviation } \pm \text { Mean }\end{array}$ & Statistical test & $P$ value \\
\hline \multirow{5}{*}{ Mother's age } & $15-20$ & $(1) 4.8$ & 13 & \multirow{5}{*}{ Fisher's exact test } & \multirow{5}{*}{0.39} \\
\hline & $20-25$ & (3) 19 & 21.7 & & \\
\hline & $25-30$ & (3)28.6 & 26.1 & & \\
\hline & $30-35$ & (5)23.8 & (8) 34.8 & & \\
\hline & $35<$ & (5)23.8 & $(1) 4.3$ & & \\
\hline \multirow{4}{*}{ Gestational age } & 1 month & (2) 9.5 & (1)4.3 & \multirow{4}{*}{ Fisher's exact test } & \multirow{4}{*}{0.57} \\
\hline & 2 months & (8)38.1 & $(13) 56.5$ & & \\
\hline & 3 months & (9) 42.9 & (6)26.1 & & \\
\hline & 4 months & (2) 9.5 & (3) 13 & & \\
\hline \multirow{2}{*}{ History of stillbirth } & Doesn't have & (3) 14.3 & $(18) 85.7$ & \multirow{2}{*}{ Fisher's exact test } & \multirow{2}{*}{0.32} \\
\hline & Have & $(4) 17.4$ & (19)82.6 & & \\
\hline \multirow{2}{*}{ History of abortion } & Doesn't have & (13)61.9 & $(18) 78.3$ & \multirow{2}{*}{ Fisher's exact test } & \\
\hline & Have & $(8) 38.1$ & (5)21.7 & & \\
\hline \multirow{5}{*}{ Education } & Illiterate & $4(19)$ & $5(21.7)$ & \multirow{5}{*}{ Fisher's exact test } & \multirow{5}{*}{0.84} \\
\hline & Elementary & $4(19)$ & $5(21.7)$ & & \\
\hline & Secondary & $8(38.1)$ & $8(34.7)$ & & \\
\hline & High school & (4) 19 & $2(8.7)$ & & \\
\hline & Higher Education & $1(4.8)$ & $3(13)$ & & \\
\hline \multirow{2}{*}{ Occupation } & Employee & $6(28.6)$ & $9(39.1)$ & \multirow{2}{*}{ Fisher's exact test } & \multirow{2}{*}{0.53} \\
\hline & Housekeeper & $15(71.4)$ & $14(60.9)$ & & \\
\hline \multirow{2}{*}{ History of hypertension } & Doesn't have & $12(57.1)$ & $16(69.6)$ & \multirow{2}{*}{ Fisher's exact test } & \multirow{2}{*}{0.53} \\
\hline & Have & $9(42.9)$ & $7(30.4)$ & & \\
\hline \multirow{2}{*}{$\begin{array}{l}\text { History of gestational } \\
\text { diabetes }\end{array}$} & Doesn't have & $13(61.9)$ & $17(73.9)$ & \multirow{2}{*}{ Fisher's exact test } & \multirow{2}{*}{0.53} \\
\hline & Have & $8(38.1)$ & $6(26.1)$ & & \\
\hline
\end{tabular}

Table 2: Comparison of the severity of nausea and its mean difference in two groups before and after the intervention

\begin{tabular}{|c|c|c|c|c|}
\hline \multirow{2}{*}{ Group time } & Control & Intervention & \multirow{2}{*}{ Statistical test } & \multirow{2}{*}{$\begin{array}{l}P \text { value } \\
0.44\end{array}$} \\
\hline & Standard deviation \pm Mean & Standard deviation \pm Mean & & \\
\hline Before intervention & $6.36 \pm 2.33$ & $6.90 \pm 2.29$ & Mann-Whitney & 0.44 \\
\hline After intervention & $5.95 \pm 2.09$ & $4.64 \pm 1.99$ & Mann-Whitney & 0.04 \\
\hline $\begin{array}{l}\text { The mean difference of nausea } \\
\text { before and after intervention }\end{array}$ & $0.41 \pm 0.24$ & $2.26 \pm 0.30$ & Mann-Whitney & 0.001 \\
\hline
\end{tabular}

\section{DISCUSSION}

The results of this study showed that there was no significant difference in the severity of nausea between the control and test groups $(p=0.44)$ before the intervention. However, the results showed that the severity of nausea in the intervention group was significantly lower than the control group (0.04). Also, according to the results of the MannWhitney test, the mean difference of nausea before and after the intervention was significant $(P=0.001)$. This means that this technique has been effective in reducing the nausea rate in pregnant women. No studies, either inside or outside the country, have been performed on the effect of relaxation therapy on nausea during pregnancy. But the results of a study titled "Investigating the effect of telephone support on the severity of nausea and vomiting in the first half of pregnancy in firstly pregnant women" by Abedian et al. showed that telephone support reduced the severity of nausea and vomiting in pregnancy (19).

A study by Bakhshi and colleagues was conducted about the effect of progressive muscle relaxation on the use of anti-nausea and vomiting drugs (antiemetic) in cancer patients treated with chemotherapy drugs. The results of this study showed that the experimental group experienced less nausea and vomiting than the control group that Metoclopramide drug has been used to a lesser extent (20).

Other findings of this study showed that there is no significant relationship between maternal age, gestational age, number of pregnancies, history of abortion, cesarean section, education level, occupation, history of hypertension, history of gestational diabetes and severity of nausea.

In this regard, the result of the study conducted by Noorani did not show a significant relationship between maternal age, gestational age, education level and nausea score $(p \geq 0.05)$, which is consistent with the findings of this study. 
The results of Soltani et al. study about the frequency of pregnancy nausea and vomiting and its related factors in pregnant women showed a significant relationship between the gestational age and the severity of nausea and vomiting, so that women aged 20 years or less had more severe nausea. In the present study, as the results show, the majority of research units were between 30 and 35 years old. Also, the results of Soltani et al. study showed that there is no significant relationship between education level and nausea in pregnancy (22), but weigel et al (2000) concluded in their study that there is a significant relationship between low education and pregnancy nausea and vomiting, which can be the cause of the possible difference between the two studies (23). The reason for the lack of correlation between the level of education and severity of nausea in the present study may be explained by an increase in the proportion of people with high education (60\%) than those with low education (40\%). Zhou et al. (1999) also reported that there is no significant relationship between the number of pregnancies with nausea and vomiting in pregnancy, which is consistent with the findings of this study (24). The results of Tabatabai Chehr's study on the comparison of the incidence of severity of nausea and vomiting between employee pregnant women and housewives ones also showed that the severity of nausea and vomiting in employee pregnant women is higher (25). The results of Yazdani et al study showed that the incidence and severity of pregnancy nausea was higher in women who had gestational diabetes (26), which this difference in outcome may be due to the low sample size and the present nature of the study.

Considering the fact that for the treatment of nausea and vomiting during pregnancy there is an enormous cost every year, including financial resources, time wasting, the cost of visiting physicians and midwifery and nursing care, and the treatment of this problem increases the hospital occupancy rate and its negative consequences, on the other hand, pharmaceutical and chemical treatments have adverse effects on both the mother and the baby, therefore, Benson's muscle relaxation technique is widely recommended in all midwives and doctors' retraining classes as well as in pregnancy counseling classes and in the same vein, other research is recommended.

\section{CONCLUSION}

Considering the positive effects of this technique in this study, without cost and ease of use and permanent availability of this technique and most importantly, being non-pharmacological, the teaching of this technique to all supporters and caregivers of mother and child, as well as pregnant mothers is recommended.

\section{ACKNOWLEDGEMENT}

This article was the result of approved student research project of Gonabad University of Medical Sciences with a code of 93.20. Hereby the Research Council of Gonabad University of Medical Sciences is appreciated. Also, the sincere cooperation of pregnant women referring to the health center of Nehbandan city and the staff of this center are appreciated.

\section{REFERENCES}

1. Louik C, Hernandez-Diaz S, Werler MM, Mitchell AA. Nausea and vomiting in pregnancy: maternal characteristics and risk factors. Paediatr Perinat Epidemiol. 2006;20(4):270-278. https://doi.org/10.1111/j.13653016.2006.00723.x PMid:16879499

2. Lacroix R, Eason E, Melzack R. Nausea and vomiting during pregnancy: A prospective study of its frequency, intensity, and patterns of change. Am J Obstet Gynecol. 2000;182(4):931-937. https://doi.org/10.1016/S00029378(00)70349-8

3. Wills G, Forster D. Nausea and vomiting in pregnancy: What advice do midwives give? Midwifery 2008; 24(4): 390-8. https://doi.org/10.1016/j.midw.2007.05.002 PMid:17850938

4. Clark SM, Constantine MM, Hankins GD. Review of NVP and HG and Early Pharmacotherapeutic Intervention, Obstet Gynecol Int. 2012;2012:252676. Epub 2011 Nov 24.

5. Eisenberg DM, Davis RB, Ettner SL, Appel S, Wilkey S, Van RM, et al. Trends in alternative medicine use in the United States, 1990-1997: results of a follow-up national survey. JAMA 1998; 280(18): 1569-75. https://doi.org/10.1001/jama.280.18.1569 PMid:9820257

6. Dooley L. Psychoanalysis of Charlotte Brontë, as a Type of the Woman of Genius. Am J Psychol. 1920;31(3):2217. https://doi.org/10.2307/1413538

7. Fairweather DV. Nause and vomiting in pregnancy. Am J Obstet Gynecol. 1968;102(1):135-75. https://doi.org/10.1016/0002-9378(68)90445-6 
8. Schorge J, et al. Williams Gynecology, 2008;1:210

9. Monahan F, Sands J, Nighbors M, Marek J, Green C. complementary and Alternative Therapies, Text book of Phipps medicalsurgical nursing. 8th ed Mosby: 2006.p.2096

10. Smeltzer S, Bare B, Hinkle J, Cheever K. Biophysical and pychological concepts in nursing practice, Brunner \& suddarths text book of medical surgical nursing. 12th ed. Philadelphia: Woltres; 2010. p. 94-97.

11. Benson H, Kotch JB, Crass KD. The relaxation response: A bridge between psychiatry and medicine. MC NA1997; 61(4):929-39.

12. Van Dixhoorn J, White A. Relaxation therapy for rehabilitation and prevention in ischaemic heart disease: a systematic review and metaanalysis. Eur J Cardiovasc Prev Rehabil 2005;12(3): 193-202. https://doi.org/10.1097/01.hjr.0000166451.38593.de PMid:15942415

13. Attar parsayi $F$. The effect of progressive muscle relaxation on state anxiety and chemotherapy-induced nausea and vomiting. Retrieved on 11.19 .2013 from http://www.Inobolfga.com/post3237

14. Cardiac rehabilitation: replication and extension. Heart \& Lung. 26(1): 31-44. Retrieved on Feb 16, 2002 from http://www.nursing.wayne.edu/faculty/rice

15. Young-Jae Kim, and Nam-Sook seo. Effects of Progressive Muscle Relaxation on Nausea, Vomiting, Fatigue, Anxiety, and Depression in Cancer Patients Undergoing Chemotherapy ((in Korean)). J Korean Oncol Nurs. 2010 Aug;10(2):171-179. https://doi.org/10.5388/jkon.2010.10.2.171

16. Sajadi $\mathrm{H}$, Vameghi M, Setareforozan A, Rafiey H, Mohgheghee Kamal SH, Nosratabadi M prevalence, risk factors and interventions of depression during pregnancy in Iranian Studies (1997-2011): A systematic review. Journal of North Khorasan University of Medical Scie $n$ ces. 2013;5(2):531.

17. Asadi F, Ebrahimi $H$, Mazluom R, Jangjou A, SaboriNoghabi M. The effect of early ambulation on nausea in patients undergoing Appendectomy. Journal of Evidence Based Care 2013; 3(6): 49-58.

18. Alexandrina Lizica D, Liliana G, Olga G. Anxiety, Stress, Depression, Oral Health Status and Behaviours in Romanian Hemodialysis Patients. Rom J Intern Med 2009; 47(2): 161-168.

19. Abedian Z, Abbaszadeh, Latifnejad Roudsari R, Shakeri MT. The Effects of Telephone Support on Stress and Perceived Social Support in Primiparous Women Experiencing Nausea and Vomiting in the First Half of Pregnancy. IJOGI 2014;17(118): 22-29.

20. Bakhshi M, Memarian R, Azad Fallah P. The Effect of Progressive Muscle Relaxation on the Dosage of Antiemetic Drugs in Cancer Patients Undergoing Chemotherapy. Ofogh-e-Danesh GMUHS Journal 2009; 15(4): 5-13.

21. Nurane sh. What makes nausea and vomiting worse during the first trimester of pregnancy. JIN 2004; $17(3)$ : 9 11.

22. Soltani, A, Kajurid M, Safavi Sh, Hosseini F. Frequency and Severity of Nausea and Vomiting in Pregnancy and the Related Factors among Pregnant Women. Iranian Journal of Nursing. 2007; 19 (48): 95-102.

23. Weigel, M.M., et al. Early pregnancy nausea and vomiting in a high-altitude Andean population. Int. J. Gynecol Obstet, 2000.

24. Zhou, Q., et al. Severity of nausea and vomiting during pregnancy: What does it predict? Birth, june 1999; 26 (2): 108-114. https://doi.org/10.1046/j.1523-536x.1999.00108.x PMid:10687575

25. Tabatabaei Chahar M, Mokhtari Far A, Salari P, Mazlom SR. Comparison of the incidence and severity of nausea and vomiting in pregnant women housewives and employees referring to Bojnourd prenatal care centers. Journal of Mashhad University of Medical Sciences 2005;46(82):68-76.

26. Yazdani SH, Bouzari Z, Faghani S. Evaluating Complications of pregnancy in patients with hyperemesis gravidarum. Journal of Kashan University of Medical Sciences, 2011; 14(4):420-24. 